\title{
Evaluasi Perencanaan Bangunan Siphon Pada Bendung Sei Padang Kab. Serdang Bedagai Sumatera Utara
}

\section{Evaluation of The Planning of Siphon Building in Sei Padang Dam, Serdang Bedagai District, North Sumatra}

\author{
Ido Rizky Harahap, Edy Hermanto \\ Program Studi Teknik Sipil, Fakultas Teknik \\ Universitas Medan Area, Indonesia \\ e-mail : rizky_ido@yahoo.com
}

\begin{abstract}
Abstrak]
Jalur saluran irigasi mulai dari intake hingga bangunan sadap terakhir kadang-kadang harus berpotongan atau bersilangan dengan berbagai rintangan antara lain jalan, saluran/alur alamiah, sungai bahkan jurang. Untuk itu diperlukan bangunan persilangan agar dapat menyeberangkan debit yang dialirkan oleh saluran dari sisi hulu ke sisi hilirnya. Bangunan siphon ini merupakan salah satu bangunan persilangan yang dibangun untuk mengalirkan debit yang dibawa oleh saluran yang jalurnya terpotong oleh sungai. Dari hasil perhitungan dimensi bangunan siphon dengan debit 6,258 $\mathrm{m}^{3} / \mathrm{dt}$, diperoleh dimensi bangunan siphon dimana lebar $(B)=1,2 \mathrm{~m}$ dan tinggi bangunan siphon $=1,7 \mathrm{~m}$, serta kehilangan tinggi energi terjadi karena adanya peralihan bentuk saluran, gesekan air dengan saluran, belokan dan saringan sebesar 0,124 m, ini menunjukkan bahwa sipon masih dapat diterima dalam membawa air. Untuk mengurangi kehilangan energi, maka lokasi siphon diusahakan pada bentang sungai terpendek, serta memperkecil jumlah belokan pada konstruksi siphon. Tulangan yang digunakan pada bangunan siphon diperoleh menggunakan D13-100 untuk tulangan pokok dan D10150 untuk tulangan bagi.
\end{abstract}

Kata Kunci : Dimensi, Kehilangan Tinggi Tekanan, Siphon.

\begin{abstract}
Irrigation channel starts from intake to the last division structure sometimes have to cut off or across with various obtacles, such as road, natural channel, river even ravine. Therefore it is required an acrossing structure in order to flow the water from upstream to downstream area. The syphon is one of several acrossing structure that constructed to flow water where the canal is crossed by river. By the calculation, Dimension of syphon with design discharge 6,258 l/s we find the width is 1,2 $\mathrm{m}$, the depth is 1,7 $\mathrm{m}$ and the head loss cause transition canal, convergence, friction, bend and trash rack are 0,124 $\mathrm{m}$. This is indicated that syphon is acceptable to bring the water. To minimize head loss and number of bends, the location of syphon should be in minimum section of river. The reinforcement of concrete syphon is used D13-100 for main reinforcement and D10-150 for lateral reinforcement.
\end{abstract}

Key Words: Dimension, Head Loss, Syphon.

How to Cite: Harahap, I., R., Edy, H. (2018). Evaluasi Perencanaan Bangunan Siphon Pada Bendung Sei Padang Kab. Serdang Bedagai Sumatera Utara. JCEBT (Journal of Civil Engineering, Building and Transportation). 2 (2): 66-74 


\section{PENDAHULUAN}

Gagalnya air masuk melalui pengambilan bebas bajayu yang berada di daerah aliran sungai (DAS) Padang, Tebing Tinggi merupakan salah satu masalah besar. Debit atau permukaan air sungai Padang hingga saat ini terus menyusut dalam beberapa bulan terakhir ini karena musim kemarau panjang. Lebih kurang 1300 hektar areal pertanian di Desa Paya Lombang, Kuta Baru, Tebing Tinggi, Kabupaten Serdang Bedagai Sumatera Utara kekeringan. Desain bendung D.I Bajayu ini mengakomodasi kepentingan irigasi ( D.I Paya Lombang 1558 Ha, D.I Langau $2000 \mathrm{Ha}$, dan D.I Bajayu $4000 \mathrm{Ha}$ ) dan pengendalian banjir kota Tebing Tinggi. Irigasi adalah usaha penyediaan dan pengaturan air untuk menunjang pertanian yang jenisnya meliputi irigasi air permukaan, irigasi air bawah tanah, irigasi pompa, dan irigasi rawa. Dengan maksud memenuhi kebutuhan air bagi pertanian dan pengendalian banjir maka diperlukan berbagai prasarana penyedia dan sumber tangkapan air. Prasarana itu dapat berupa bangunan - bangunan dimulai dari bangunan hulu ( induk ) sebagai pengambil air dari aliran air ( sungai ) sampai dengan bangunan - bangunan pada jaringan irigasi. Jaringan irigasi adalah satu kesatuan saluran dan bangunan yang diperlukan untuk penyediaan, pembagian, pemberian, penggunaan dan pembuangan air irigasi ( PP No.20 tahun 2006 ). Tolak ukur keberhasilan pengelolaan jaringan irigasi adalah efesiensi dan efektifitas saluran pembawa air. Pada hilir bendung ini terdapat saluran pembawa air yang melintasi sungai. Sehingga diperlukan bangunan siphon untuk membawa air agar mampu mengairi areal sawah sesuai dengan yang diharapkan. Berdasarkan uraian pada latar belakang masalah dapat diidentifikasikan beberapa masalah yang muncul dalam perencanaan bangunan pelengkap dan bangunan bagi antara lain :

Bagaimanakah analisa perhitungan bangunan Siphon?
Apakah bangunan Siphon dapat mencapai keefektifan jaringan irigasi?

Seberapa besarkah pengaruh bangunan Siphon dalam keberhasilan jaringan irigasi?

Arti irigasi pada umumnya adalah usaha mendatangkan air dengan membuat bangunan-bangunan dan saluran-saluran untuk mengalirkan air guna keperluan pertanian, membagi-bagikan air kesawahsawah atau lading-lading dengan cara yang teratur dan membuang air yang tidak diperlukan lagi ke sungai setelah air digunakan sebaik-baiknya. Sistem irigasi di Indonesia yang umumnya bergantung kepada cara pengambilan air sungai dan dimaksudkan untuk mengairi persawahan dapat dibedakan menjadi irigasi pedesaan dan irigasi pemerintah. Pembedaan itu berdasarkan pengelolalaanny. Sistem irigasi desa bersifat komunal dan tidak menerima bantuan dari pemerintah pusat. Pembangunan dan pengelolaannya seluruh jaringan irigasi dilakukan sepenuhnya oleh masyarakat. Sedangkan sistem irigasi yang tergantung pada bantuan pemerintah dibagi kedalam tiga kategori, yaitu irigasi teknis, irigasi semi teknis dan irigasi sederhana. Keberadaan bangunan irigasi diperlukan untuk menunjang pengambilan dan pengaturan air irigasi. Beberapa jenis bangunan irigasi yang sering dijumpai dalam praktek irigasi antara lain :

\section{Bangunan utama;}

Bangunan pembawa;

Bangunan bagi;

Bangunan sadap;

Bangunan pembuang dan penguras;

Bangunan pelengkap.

Dalam hal ini yang akan dibahas adalah perhitungan perencanaan bangunan Siphon pada jaringan irgasi. Kebutuhan air irigasi adalah jumlah volume air yang diperlukan untuk memenuhi kebutuhan evapotranspirasi, kehilangan air, kebutuhan air untuk tanaman dengan memperhatikan jumlah air yang diberikan oleh alam melalui hujan dan kontribusi air tanah. Faktor- faktor 
yang mempengaruhi besarnyaair yang perlu disediakan dengan sistem irigasi adalah:

Curah hujan;

Kontribusi air tanah;

Evapotranspirasi;

Perkolasi

Aliran air dalam suatu saluran dapat berupa Aliran saluran terbuka (open channel flow) dan aliran saluran tertutup (pipe flow). Keduanya dalam beberapa hal adalah sama, perbedaannya yaitu aliran pada saluran terbuka harus memiliki permukaan bebas yang dipengaruhi tekanan udara bebas, sedangkan aliran pada pipa tidak dipengaruhi oleh tekanan udara secara langsung kecuali oleh tekanan hidrolik. Dapat dilihat pada Gambar 1.

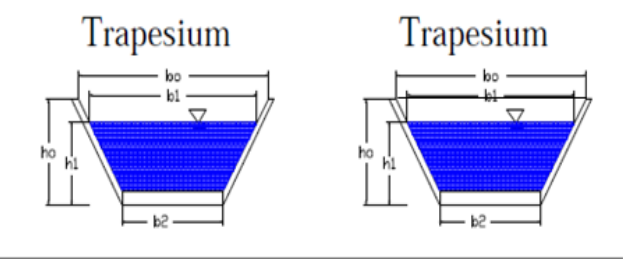

Empat Persegi pajang Empat Persegi pajang
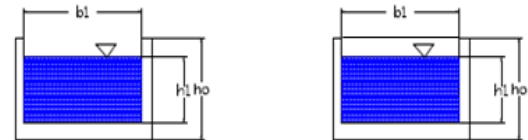

Setengah Lingkaran Setengah Lingkaran
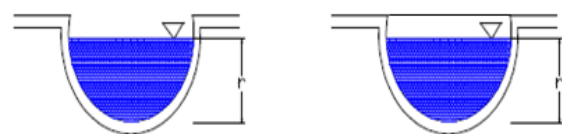

Gambar 1. Saluran Terbuka dan Tertutup

Pada umumnya perhitungan saluran terbuka hanya digunakan pada aliran tetap dengan debit $Q$, sehingga tinggi banjir rencana di hilir bendung dihitung dengan rumus Manning sebagai berikut:

$$
\mathrm{Q}=\mathrm{A} \times \mathrm{V}
$$

Dimana:

$\mathrm{A}=$ luas penampang melintang saluran $\left(\mathrm{m}^{2}\right)$

$\mathrm{V}=$ kecepatan rata-rata aliran $(\mathrm{m} / \mathrm{dt})$
Dalam hal ini untuk mencari kecepatan rata-rata aliran digunakan rumus Stickler:

$$
\mathrm{V}=\mathrm{K} \times \mathrm{R}^{2 / 3} \times \mathrm{I}^{1 / 2}
$$

\section{Dimana :}

$\mathrm{K}=$ koefisien kekasaran saluran

$\mathrm{R}=$ jari-jari hidrolis $(\mathrm{m})$

$\mathrm{I}=$ kemiringan dasar saluran

Potongan melintang saluran yang paling ekonomis adalah saluran yang dapat melewatkan debit maksimum untuk luas penampang basah, kekasaran, dan kemiringan dasar tertentu. Berdasarkan persamaan kontinuitas, tampak jelas bahwa untuk luas penampang melintang tetap, debit maksimum dicapai jika kecepatan aliran maksimum. Penampang hidrolis terbaik atau paling efisien kadangkadang disebut juga tampang ekonomis.

Bangunan siphon merupakan salah satu bangunan persilangan yang dibangun untuk mengalirkan debit yang dibawa oleh saluran yang jalurnya terpotong oleh lembah dengan bentang panjang atau terpotong oleh sungai. Bangunan siphon berupa saluran tertutup yang dipasang mengikuti bentuk potongan melintang sungai atau lembah untuk menyeberangkan debit dari sisi hulu ke sisi hilir. Bangunan siphon (berupa saluran tertutup berpenampang lingkaran atau segi empat) dipasang dibawah dasar sungai, atau bisa juga dipasang di atas permukaan tanah jika melintasi lembah (cekungan). Konstruksi siphon jika penampang melintang berupa segi empat biasanya dibuat dari beton bertulang (reinforced concrete), jika penampang melintang berupa lingkaran biasanya dibuat dari baja. Untuk mencegah adanya sedimentasi pada saat debit di dalam siphon mengecil, biasanya digunakan tipe pipa rangkap. Pada saat debit di dalam siphon mengecil, jalur satu ditutup, jalur lainnya dibuka sehingga kecepatan aliran didalam siphon tetap bisa mengangkut sediment ke hilirnya. Konstruksi siphon harus dipilih pada lokasi yang panjang 
bentang sungainya minimum, agar biaya konstruksinya hemat, serta kehilangan energinya kecil. Untuk mencegah sedimentasi aliran dalam siphon harus tinggi. Tetapi, kecepatan yang tinggi menyebabkan bertambahnya kehilangan tinggi energi. Oleh sebab itu keseimbangan antara kecepatan yang tinggi dan kehilangan tinggi energi yang diizinkan harus tetap dijaga. Kecepatan aliran dalam siphon harus dua kali lebih tinggi dari kecepatan normal aliran dalam saluran, dan tidak boleh kurang dari $1 \mathrm{~m} / \mathrm{dt}$, lebih disukai lagi kalau tidak kurang dari 1,5 $\mathrm{m} / \mathrm{dt}$. Kecepatan maksimum sebaiknya tidak melebihi $3 \mathrm{~m} / \mathrm{dt}$.

Kehilangan tinggi energi pada siphon terdiri dari kehilangan energi akibat gesekan, kehilangan energi akibat belokan, kehilangan energi akibat peralihan dan kehilangan energi akibat saringan. Kehilangan-hilangan energi ini dapat dihitung menggunakan rumus sebagai berikut:

(Y.C Lim.1981. Hydraulic Design Practice Of Canal Structure halaman 113)

Kehilangan energi pada pintu masuk (inlet)

Akibat gesekan (friction)

Kehilangan energi akibat gesekan dapat dihitung dengan persamaan berikut:

$\Delta \mathrm{Hf}=\mathrm{L} 1 \times \frac{\mathrm{I} 1+\mathrm{I} 2}{2}$

Dimana:

$I=\left(\frac{V}{\frac{1}{n} \times R^{2 / 3}}\right) \ldots \ldots \ldots \ldots \ldots \ldots \ldots$

$\mathrm{I}=$ kemiringan saluran

$\Delta \mathrm{Hf}=$ kehilangan energi akibat

$$
\begin{aligned}
& \text { gesekan }(\mathrm{m}) \\
& \mathrm{L}=\text { panjang saluran }(\mathrm{m}) \\
& \mathrm{n}=\text { koefisien kekasaran saluran }\left(\frac{\mathbb{1}}{K}\right)
\end{aligned}
$$

$\mathrm{V}=$ kecepatan aliran $(\mathrm{m} / \mathrm{dt})$
Akibat

peralihan/penyempitan

(convergence)

Kehilangan energi pada peralihan masuk dan peralihan keluar dinyatakan memakai rumus Borda:

$$
\Delta \mathrm{Hc}=\xi \times \frac{\left(\mathrm{V} 2^{2}-\mathrm{V} 1^{2}\right)}{2 g}
$$

Dimana :

$\Delta H c$

$$
=\text { kehilangan energi akibat }
$$

peralihan (m)

$\mathrm{V}=$ kecepatan aliran di dalam siphon $(\mathrm{m} / \mathrm{dt})$

Va $=$ kecepatan aliran di saluran (m/dt)

$\xi=$ faktor kehilangan energi

yang bergantung kepada bentuk hidrolis peralihan dan apakah kehilangan itu peralihan masuk atau keluar.

Kehilangan tinggi energi air pada kisi-kisi penyaring dapat dihitung dengan:

$$
\Delta H \gamma=3 \varphi\left(\frac{s}{b}\right)^{\frac{4}{3}} \times \frac{\mathrm{V}^{2}}{2 \mathrm{~g}} \sin \alpha \ldots \ldots \ldots . . . .(6)
$$

\section{Dimana :}

$\Delta \mathrm{HY}_{\mathrm{Y}}=$ kehilangan energi akibat

$$
\text { saringan (m) }
$$

$\mathrm{V}=$ kecepatan aliran di

$$
\text { siphon, }(\mathrm{v}=2 \mathrm{~m} / \mathrm{dt})
$$

$\varphi \quad=$ koefisien berdasarkan bentuk profil batang

jeruji saringan, fakor bentuk $(2,4$ untuk segi empat, dan 1,8 untuk jeruji bulat)

$$
\begin{aligned}
& \mathrm{s}=\text { tebal batang jeruji saringan } \\
& (\mathrm{mm}) \\
& \mathrm{b}=\text { jarak antar batang jeruji }(\mathrm{m}) \\
& \alpha \quad=\text { kemiringan batang jeruji } \\
& \quad \text { terhadap horizontal }
\end{aligned}
$$

Kehilangan energi pada saluran siphon (conduit)

Akibat gesekan (friction)

Kehilangan energi akibat gesekan dapat dihitung dengan persamaan berikut: 


$$
\Delta \mathrm{Hf}=\mathrm{L} 2 \times \mathrm{I} 2
$$

Dimana:

$\Delta \mathrm{Hf} \quad=$ kehilangan energi

\section{akibat gesekan (m)}

L2 = panjang saluran siphon $(\mathrm{m})$

I2 = kemiringan saluran siphon $(\mathrm{m})$

Akibat belokan (bend)

Bagian siku dan tikungan dalam siphon atau pipa menyebabkan perubahan arah aliran dan, sebagai akibatnya, perubahan pembagian kecepatan pada umumnya. Kehilangan energi akibat belokan jumlahnya lebih besar dari kehilangan akibat gesekan. Kehilangan energi akibat belokan dapat dihitung dengan:

$$
\Delta \mathrm{Hb}=\mathrm{kb} \frac{\mathrm{V}}{2 \mathrm{~g}}
$$

Dimana :

$\Delta \mathrm{Hb}=$ kehilangan energi di

bagian

$$
\text { belokan (m) }
$$

$\mathrm{V}=$ kecepatan aliran $(\mathrm{m} / \mathrm{dt})$

$\mathrm{kb} \quad=$ koefisien akibat belokan

$\mathrm{g}=$ percepatan gravitasi $\left(\mathrm{m} / \mathrm{dt}^{2}\right)$ (outlet)

Kehilangan energi pada pintu keluar

Akibat gesekan

Kehilangan energi akibat gesekan dapat dihitung dengan persamaan berikut:

$\Delta \mathrm{Hf}=\mathrm{L} 3 \times \frac{\mathrm{I} 2+\mathrm{I} 3}{2}$

Dimana:

$\mathrm{I}=\left(\frac{\mathrm{V}}{\frac{1}{\mathrm{n}} \times R^{2 / 3}}\right)$

$\mathrm{I}=$ kemiringan saluran

$\Delta \mathrm{Hf}=$ kehilangan energi

akibat gesekan (m)
$\mathrm{L}=$ panjang saluran $(\mathrm{m})$

$\mathrm{n}=$ koefisien kekasaran saluran $\left.\frac{(1}{K}\right)$

$\mathrm{V}=$ kecepatan aliran $(\mathrm{m} / \mathrm{dt})$

Akibat pelebaran (divergence)

Kehilangan energi akibat gesekan dapat dihitung dengan:

$\Delta \mathrm{Hd}=$ fo $\times\left(\frac{\mathrm{V}^{2}-\mathrm{V} 3^{2}}{2 \mathrm{~g}}\right) \ldots \ldots \ldots$

Dimana :

$\Delta \mathrm{Hd}=$

kehilangan energi akibat pelebaran (m)

fo $\quad=$ koefisien akibat pelebaran $(0,3)$

V2 = kecepatan di dalam siphon $(\mathrm{m} / \mathrm{dt})$

V3 = kecepatan di saluran (m/dt)

$\mathrm{g}=$ percepatan gravitasi $\left(\mathrm{m} / \mathrm{dt}^{2}\right)$

\section{METODE PENELITIAN}

Mengumpulkan basis pengetahuan (knowledge base) mengenai jaringan irigasi dari beberapa buku yang berkenaan dengan sistem perencanaan irigasi.

Mengumpulkan data-data yang diperlukan terdiri dari data primer dan data sekunder. Ada pun data primer yaitu data yang diperoleh dengan pengamatan langsung di lapangan yaitu melakukan survey terhadap pengembangan jaringan irigasi yang tersedia sedangkan data sekunder adalah data yang diperoleh dari instansi-instansi terkait dalam permasalahan dan penyelesaian pengembangan jaringan irigasi.

\section{HASIL DAN PEMBAHASAN}

Perhitungan Disain Hidrolis Siphon. Dengan cara coba-coba maka dicoba untuk dimensi siphon dengan:

$$
\begin{aligned}
& \mathrm{h}=1,7 \mathrm{~m} \\
& \mathrm{~A}=1,2 \times 1,7=2,04 \mathrm{~m}^{2} \\
& \mathrm{P}=(2 \times 1,2)+(2 \times 1,7)=5,80 \mathrm{~m} \\
& \mathrm{R}=2,04 / 5,80=0,352 \mathrm{~m} \\
& \mathrm{Q}=1,5 \times 2,04=3,10 \mathrm{~m}^{3} / \mathrm{dt} \sim
\end{aligned}
$$$$
\text { Qrencana (ok) }
$$ 

Energi

Perhitungan Kehilangan Tinggi

Pada Pintu Masuk (inlet)

$\mathrm{Q}=6,258 \mathrm{~m}^{3} / \mathrm{dt}$

$\mathrm{h}=1,2 \mathrm{~m}$

$\mathrm{b}=4,0 \mathrm{~m}$

$\mathrm{m}=1,5$

$\mathrm{L}=5,0 \mathrm{~m}$

$A=6,96 \mathrm{~m}^{2}$

$\mathrm{K}=60$

$\mathrm{V} 1=\frac{6,258}{6,96}=0,89 \mathrm{~m} / \mathrm{dt}$

$\mathrm{P}=4,0+21,2 \sqrt{1,5^{2}+1}=8,32 \mathrm{~m}$

$\mathrm{R}=\frac{6,96}{8,32}=0,83 \mathrm{~m}$

$\mathrm{n}=\frac{1}{60}=0,016$

$\mathrm{I} 1=\left(\frac{0,89}{\frac{1}{0,016} \times 0,83^{\frac{2}{3}}}\right)^{2}=0,000285$

Akibat gesekan (friction)

$\Delta \mathrm{Hf}=5,0 \times \frac{0,000285+0,00177}{2}$

$=0,00514 \mathrm{~m}$

Akibat peralihan/penyempitan

(convergence)

$\Delta \mathrm{Hc}=0,5 \times \frac{1,5^{2}-0,89^{2}}{2 \times 9,8}=0,037 \mathrm{~m}$

Akibat saringan (trash rack)

Bentuk batang sgreen diambil bulat, sehingga,

$$
\begin{aligned}
& \varphi=1,8 \\
& \mathrm{~s}=22 \mathrm{~mm}=0,022 \mathrm{~m} \\
& \mathrm{~b}=0,10 \mathrm{~m} \\
& \alpha=70^{\circ} \\
& \Delta \mathrm{H} \gamma=3 \times 1,8\left(\frac{0,022}{0,10}\right)^{\frac{4}{3}} \times \frac{0,89^{2}}{2 \times 9,8}
\end{aligned}
$$

$\times \sin 70=0,027 \mathrm{~m}$

$\Delta$ Htotal $=0,00514+0,037+0,027$

$=0,0694 \mathrm{~m}$

Pada Saluran Siphon (conduit)

$\mathrm{Q}=3,129 \mathrm{~m}^{3} / \mathrm{dt}$

$\mathrm{h}=1,7 \mathrm{~m}$

$\mathrm{b}=1,2 \mathrm{~m}$

$\mathrm{m}=0$

$\mathrm{L}=9,0 \mathrm{~m}$

$\mathrm{A}=2,04 \mathrm{~m}^{2}$

$\mathrm{K}=70$

$\mathrm{V} 2=1,5 \mathrm{~m} / \mathrm{dt}$

$\mathrm{P}=5,80 \mathrm{~m}$

$\mathrm{R}=0,352 \mathrm{~m}$

$\mathrm{n}=\frac{1}{70}=0,014$

$\mathrm{I} 2=\left(\frac{1,53}{\frac{1}{0,014} \times 0,352^{\frac{2}{3}}}\right)^{2}=0,00177$

Akibat gesekan (friction)

$\Delta \mathrm{Hf}=9,0 \times 0,00177=0,016 \mathrm{~m}$

Akibat belokan (bend)

Tan $\Delta 1=\frac{1}{2}=0,5$

$\Delta 1=\arctan (0,5)=26,565^{\circ}$

$\operatorname{Tan} \Delta 2=\frac{1}{2,5}=0,4$

$\Delta 1=\arctan (0,4)=21,801^{\circ}$

$\Delta \mathrm{Hb}=(0,09+0,07) \times \frac{1,5}{2 \times 9,8}$

$=0,012 \mathrm{~m}$

$\Delta$ Htotal $=0,016+0,012=0,028 \mathrm{~m}$ 
Pada Pintu Keluar (Outlet)

$\mathrm{Q}=6,258 \mathrm{~m}^{3} / \mathrm{dt}$

$\mathrm{h}=1,2 \mathrm{~m}$

$\mathrm{b}=4,0 \mathrm{~m}$

$\mathrm{m}=1,5$

$\mathrm{L}=5,0 \mathrm{~m}$

$A=6,96 \mathrm{~m}^{2}$

$\mathrm{K}=60$

$\mathrm{V} 3=\frac{6,258}{6,96}=0,89 \mathrm{~m} / \mathrm{dt}$

$\mathrm{P}=4,0+21,2 \sqrt{1,5^{2}+1}=8,32 \mathrm{~m}$

$\mathrm{R}=\frac{6,96}{8,32}=0,83 \mathrm{~m}$

$\mathrm{n}=\frac{1}{60}=0,016$

$\mathrm{I} 3=\left(\frac{0,89}{\frac{1}{0,016} \times 0,83^{\frac{2}{3}}}\right)^{2}=0,000285$

Akibat gesekan (friction)

$\Delta \mathrm{Hf}=5,0 \times \frac{0,000285+0,00177}{2}$

$=0,00514 \mathrm{~m}$

Akibat pelebaran (divergence)

$\Delta \mathrm{Hd}=0,3 \times \frac{1,5^{2}-0,89^{2}}{2 \times 9,8}$

$=0,022 \mathrm{~m}$

$\Delta$ Htotal $=0,00514+0,022=0,027 \mathrm{~m}$

$\Delta$ Htotal keseluruhan

$=0,0694+0,028+0,027=0,1244 \mathrm{~m}$

Penulangan Siphon

Plat Atas

Data-data:

$\mathrm{K}=175$

$\mathrm{Mu}=$

$$
\mathrm{M}_{\mathrm{BA}^{(-)}}=1,337 \mathrm{tm}
$$

Perhitungan:

$\mathrm{f}^{\prime} \mathrm{c}=\mathrm{K}$ x 0,083 = 14,53 Mpa

$\mathrm{ds}=5 \mathrm{~cm}=50 \mathrm{~mm}$

$\mathrm{d}=25 \mathrm{~cm}=250 \mathrm{~mm}$

$\mathrm{k}=\frac{\mathrm{M}_{\mathrm{u}}}{\emptyset \mathrm{bd}^{2}}=\frac{13,37 \times 10^{6}}{0,8 \times 1000 \times 250^{2}}$

$=0,267 \mathrm{Mpa}<\mathrm{Kmax}$

$a=\left(1-\sqrt{1-\frac{2 \times k}{0,85 \times f^{\prime} c}}\right) \times d$

$=\left(1-\sqrt{1-\frac{2 \times 0,267}{0,85 \times 14,53}}\right) \times 250$

$=5,464 \mathrm{~mm}$

Tulangan Pokok

$A_{s}=\frac{0,85 \times f^{\prime} \mathrm{c} \times \mathrm{aXb}}{\mathrm{fy}}=\frac{0,85 \times 14,53 \times 5,464 \times 1000}{320}=210,88 \mathrm{~mm}^{2}$

$\mathrm{f}^{\prime} \mathrm{c} 31,36 \quad \mathrm{Mpa}$, jadi As, $\mathrm{u} \geq \frac{1,4}{\mathrm{fy}} \times \mathrm{b} \times \mathrm{d}=\frac{1,4}{320} \times 1000 \times 250=$ $1093,75 \mathrm{~mm}^{2}$

Dipilih yang besar, jadi As, u = 1093,75 mm.

Jarak tulangan,

$\mathrm{s}=\frac{\frac{1}{4} \times \pi \times \mathrm{D}^{2} \times \mathrm{S}}{\mathrm{As}, \mathrm{u}}$

$=\frac{\frac{1}{4} \times \pi \times 13^{2} \times 1000}{1093,75}$

$=121,35 \mathrm{~mm}$

$\mathrm{s} \leq(3 \times \mathrm{h}=3 \times 30=90 \mathrm{~mm})$

Dipilih yang kecil, jadi dipakai $\mathrm{S}=90$ $\mathrm{mm}$.

Luas tulangan $=\frac{\frac{1}{4} \times \pi \times \mathrm{D}^{2} \times \mathrm{S}}{\mathrm{s}}$ 


$$
\begin{aligned}
& =\frac{\frac{1}{4} \times \pi \times 13^{2} \times \times 1000}{90} \\
& =1474,803 \mathrm{~mm}^{2}>\text { As,u ... ok } \\
& \text { Dipakai tulangan D13-100 } \\
& \mathrm{n}=\frac{1093,75}{1 / 4 \times \pi \times 13^{2}}=8,24 \sim 9 \text { batang }
\end{aligned}
$$

Tulangan Bagi

As, $\mathrm{b}=20 \%$ As, $\mathrm{u}=20 \% \times 1474,803=$ $294,96 \mathrm{~mm}^{2}$.

$A s, b=0,002 \times b \times h=0,002 \times 1000 \times 30=$ $60 \mathrm{~mm}^{2}$.

Dipilih yang besar, jadi Asb,u $=294,96$ $\mathrm{mm}^{2}$.

Jarak tulangan,

$$
\begin{aligned}
& \mathrm{s}=\frac{\frac{1}{4} \times \pi \times \mathrm{D}^{2} \times \mathrm{S}}{\mathrm{As}, \mathrm{u}} \\
& =\frac{\frac{1}{4} \times \pi \times 10^{2} \times 1000}{1093,75}
\end{aligned}
$$

$=266,273 \mathrm{~mm}$

$\mathrm{s} \leq(5 \times \mathrm{h}=5 \times 30=150 \mathrm{~mm})$

Dipilih yang kecil, jadi dipakai $S=150$ mm.

Luas tulangan $=\frac{\frac{1}{4} \times \pi \times \mathrm{D}^{2} \times \mathrm{S}}{\mathrm{s}}$

$$
=\frac{\frac{1}{4} \times \pi \times 10^{2} \times \times 1000}{150}
$$

$=523,598 \mathrm{~mm}^{2}>$ Asb,u $\ldots$ ok

Dipakai tulangan D10-150

$\mathrm{n}=\frac{294,96}{1 / 4 \times \pi \times 10^{2}}=3,75 \sim 4$ batang

Hasil perhitungan tulangan digambarkan pada Gambar 2.

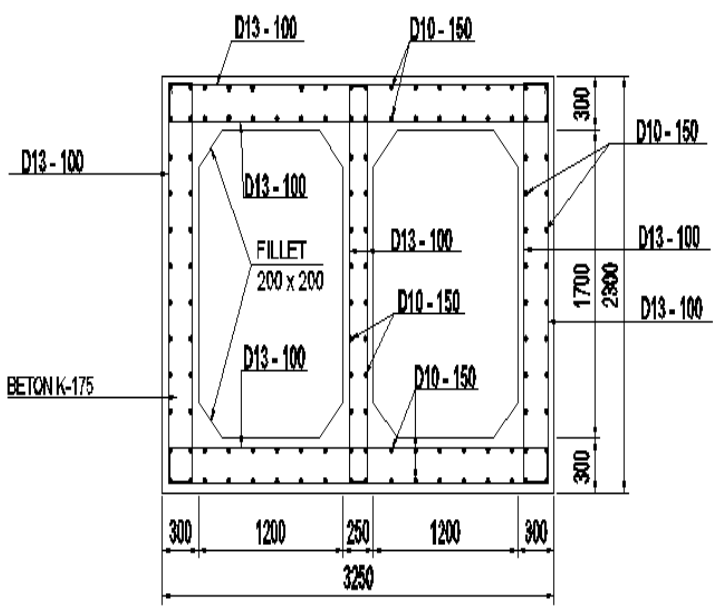

Gambar 2. Potongan Tulangan Siphon

\section{SIMPULAN}

Dari hasil perhitungan dimensi bangunan siphon dengan debit 6,258 $\mathrm{m}^{3} / \mathrm{dt}$, diperoleh dimensi bangunan siphon dimana lebar $(B)=1,2 \mathrm{~m}$ dan tinggi muka air bangunan sihon $=1,7 \mathrm{~m}$. Berdasarkan hasil perhitungan kehilangan tinggi energi, menunjukkan bahwa efektifitas sistem drainase saluran pembawa air berkurang karena terjadi pengurangan tinggi tekanan air sebesar 0,124 m. Ini dikarenakan adanya peralihan bentuk saluran dan saringan. Total kehilangan tinggi energi harus lebih kurang 100\% lebih kecil dari perbedaan tinggi muka air, ini menunjukkan bahwa sipon masih dapat diterima dalam membawa air. Berdasarkan hasil perhitungan tulangan, maka tulangan yang digunakan pada bangunan siphon diperoleh menggunakan D13-100 untuk tulangan pokok dan D10150 untuk tulangan bagi.

\section{DAFTAR PUSTAKA}

Direktorat Jenderal Pengairan. ( 1986 ). Kriteria Perencanaan Bagian Jaringan Irigasi KP-01, Bandung: CV. Galang Persada.

Direktorat Jenderal Pengairan. ( 1986 ). Kriteria Perencanaan Bagian Jaringan Irigasi KP-04, Bandung: CV. Galang Persada.

Direktorat Jenderal Pengairan. ( 1986 ). Kriteria Perencanaan Bagian Jaringan Irigasi KP-03, Bandung: CV. Galang Persada. 
LIM, Y.C. And D.S.KIM. ( 1981 ). Hydraulic Design Practice of Canal Structure. Korea: Sisa Munwha Printing Co.

Ludiana, Tri dan Wilhelmus. 2015. Evaluasi Kinerja Jaringan Irigasi Bendungan Tilong Kecamatan Kupang Tengah Kabupaten Kupang. Jurnal Teknik Sipil. 4(1). 1-13.

Peraturan Pemerintah, No. 20. 2006. Tentang Irigasi.

Syahbana, Arifan. 2014. Rekayasa Hidrolika Kestabilan Lereng Dengan Sistem Siphon. Jurnal e-ISSN2354-6638 (online), diakses 2 Maret 2017. 